\title{
Study on Agricultural Insurance Based on Products Marketing
}

\author{
Lixin Tang \\ School of Management, Yangtzeu University, Jingzhou 434023, China \\ E-mail: tanglixin@yeah.net
}

\begin{abstract}
Agricultural insurance is a kind of important measure to stable agricultural production and countryside social life. But in China, the development of agricultural insurance faces up with difficult position. This paper analyzes the characteristics of agricultural insurance, introduces overseas agricultural insurance situation, and then puts forward innovative thoughts on agricultural insurance. Agricultural insurance should put a lot of efforts in marketing pattern.
\end{abstract}

Keywords: Agricultural insurance, Marketing pattern, Grant-in-aid

\section{Introduction}

The No.1 documents issued in 2007 by central recently focus the attention on developing modern agricultural activity again. According to statistics of our country, agricultural insurance has increased rapidly in 2006, the income of insurance expenditure got up to 8.5 billion which has increased 16.2 percent compared with the past .The agricultural has become the new point of growth in the insurance business. Our country is a great agricultural nation and natural disaster area. So it's necessary and urgent to accelerate our country insurance innovative.

\section{The property of agricultural insurance}

\subsection{The natural attribute of agricultural insurance}

The agricultural insurance has high risk, high payment limited anticipated income etc. Moreover, because of the dispersed service the management expense and the operation cost are all very high. These characteristics have decided the payment ratio of agricultural is higher than the safety line of the normal management in insurance company. According to pertinent data demonstration, from 1985 to 2004, our country Agricultural insurance has only realized two years meager profit, other 18 years was lose completely, the integrate ratio of Agricultural had exceeded 120 percent by far. In order to decrease the ratio of insurance fee and the management cost of insurance company. The integrate ratio of agricultural every government all gives different policy allowance and favorable measures to agricultural insurance so as to guarantee the agricultural insurance has well developed.

\subsection{The society attribute of agricultural insurance}

The agricultural special status had decided the agricultural insurance is not the pure commodity, but is the public product. It has intensity exterior public and policy type. In the developed country, the government must offer this kind of business operating subsidy, the financial tax revenue preferential benefit, with administrative convenient measure. In order to keep the family income stability, the USA government advocates Agricultural insurance strongly so that farmers, even if due to the loss caused by natural disasters, the payment of insurance can also help them keep the life stable and renew the Agricultural production, thus prevent the bankruptcy of farmers from spreading throughout the basis of economic development and social stability of USA.

\subsection{The politic attribute of agricultural insurance}

Our country is a great country which has 23 percent of rural population in the whole; the development of agriculture and the stability of the country have an important effect on our country's entire national economy, as well as the coordinated development of country's stability and unity and the steady of development. The development of agricultural insurance can be divided into decentralization and transfer of agricultural risk, which is a significant guarantee to protect the interests of farmers and achieve sustainable development of agriculture under the condition of the market economy. Our country mainly depends on government financial allowance to solve the risks and retrieve peasant agriculture losses for a long period of time. However, because of the limited of the government financial fund, always "emergency hard on the poor", can't solve the problem fundamentally. In contrast, the mature experience of the 
overseas as well as some areas' spontaneous practice in domestic shows that changing into the method by marketization, avoiding the risk and compensation loss by the means of insurance is effective.

\section{The situation of the agricultural insurance in oversea}

\subsection{The agricultural insurance of America}

In 1938, America promulgated "Federal Crop Insurance Act" and at the same year set up a government agency under the act. The Federal Crop Insurance, which responsibility is operating and managing the nation crop. Beginning in 1939 the implementation of the government crop insurance schemes, thus the federal government opened a history of agricultural insurance. The most prominent feature of agricultural insurance to fund the establishment of official country is crop insurance companies. Its operating system has experienced from the "single-track" and then to the "single-track system" ever-charging. From 1939 to 1980, the federal crop insurance company, at this stage is operated by government agencies alone "single-track system". From 1980 to 1996, in order to improve the participate rate of crop insurance and reduce the supervision costs of crop insurance, the operating system in the US began the introduction of private and commercial insurance companies and insurance agents to participate in crop insurance operatives and product sales, that is, government agencies and commercial co-operation of agricultural insurance company's "dual track". After 1996, the Federal Crop Insurance crop began to exit the business operated by the government of the policy of incentives and subsidies gradually, the private insurance companies start to operate all of the agricultural insurance agent business directly.

American Agricultural Insurance Company has entered a private company to run a separate "single-track system" time. In this "single-track" system, the Federal crop insurance companies are only responsible for formulating regulations to carry out auditing and oversight functions and to provide reinsurance. At present, the model of United States agricultural insurance business can be summarized as follows: private insurance companies operating the original insurance, the government providing reinsurance.

\subsection{The agricultural insurance of Japanese}

The Japanese government has always attached importance to the legal construction of agricultural insurance, early in 1929 has enacted "Livestock Insurance Act", then in 1938 "Agricultural Insurance Act" has enacted, in 1947 "Agricultural Disaster Compensation Law", then in accordance with the needs of agricultural development, in 1957, 1963, 1966, 1972, 1978, 1985 and 2003, the legal system of agricultural insurance was amended, which provided a strong institutional guarantee for the continued development of Japanese agricultural insurance. The Japanese government premium subsidies to farmers, and the higher insurance rates, the more subsidies of the state treasury. The Government has also undertaken to provide agricultural insurance services team grant (except for liberty insurance business), and has offered reinsurance business for the Masonic federation.

Japanese agricultural insurance adopts the form of Masonic portfolio. Agricultural insuranceis based on cities, towns and villages of the agricultural portfolio for Masonic as the Grass-roots organizations, which is voluntary cooperation of farmers organizations, and conducts agricultural insurance business directly; county-level institutions (both, prefectures) have established the agricultural portfolio Masonic United and have assumed Masonic portfolio reinsurance; the Government as the leading organ of the agricultural insurance portfolio undertake all the re-insurance excluding the share of Masonic insurance. The system of government leadership and agricultural Masonic portfolio that combines up-down pattern of agricultural insurance organizations has formed. Under normal circumstances, the above-mentioned organizations assume their respective proportion of liability insurance as follows: Masonic portfolio 10-20\%, Federation of $20-30 \%$, the Government $50-70 \%$. Encountered in heavy disasters, the Government assumes $80-100 \%$ of insurance claims. It shows that Japanese agricultural insurance business model is: the original operating Masonic portfolio insurance, Masonic federation provided a combination of reinsurance, the second-level reinsurance provided by the government.

\section{Thoughts on Chinese agricultural insurance}

Chinese agricultural insurance should not only learn the foreign successful experiences in agricultural insurance, but also find their own suitable agricultural insurance development models: on the one hand the Government needs play an important role in the agricultural insurance, on the other hand, insurance companies should play their subjective initiative, make efforts at promotion modem.

\subsection{Intensify the government support to agricultural insurance}

3.1.1 Intensify agricultural insurance legislation to protect the development of agricultural insurance in the form of legal ,to ensure that the interests of agricultural producers; the Government should be in the functions and roles in carrying out agricultural insurance with a clear legal form ,to avoid government support agricultural insurance randomness, and to increase awareness of farmer's insurance. 
3.1.2 To lighten the scope of agricultural insurance business appropriately and carry out "in order to raise the risk insurance." With the improvement income levels of farmers, the farmers have a lot of insurance needs. Establishing the "big agricultural insurance" concept will include agricultural insurance, including rural areas, agriculture, farmers and other related insurance business into a comprehensive business scope of agricultural insurance companies, that is, we started up traditional farming, aquaculture and other policies agricultural insurance business, at the same time, carried out all agriculture-related property insurance, liability insurance and life, accidental injury insurance business, also boarded in the agricultural insurance implement "based on agriculture (Village insurance) premium farmers (village dangerous)", to make Policy-oriented insurance agency to make additional commercial insurance, to use commercial insurance policy to make up for loss of profits, in order to achieve the means of policy and market a combination, the two complementary advantages.

3.1.3 The Government makes financial subsidies, tax concessions to agricultural insurance. Support for agricultural insurance should make full use of policy instruments to formulate preferential and flexible support policy to support the development of agricultural insurance.

\subsection{In terms of insurance companies should make an affect even more miserable}

\subsubsection{The design agricultural product must act according to circumstances}

In 2003, PICC Property Insurance Company in Jilin Province has launched the "Jin Lu Yin He" series of insurance products, including comprehensive agricultural risks insurance, the self-insurance of rural family and so on. Currently the part of the series products has been extended to the whole country and has gotten well social benefits. At the same time, Jilin People's Insurance National Insurance also have increased demand for insurance to the scarcity of national forest resources and plant fast-growing trees situation, have adjusted a forest fire products, and have developed the forest insurance effectively; In addition, the business of rural small credit insurance business also have been exploited.

In 2004, Jilin People's Insurance focus on the design and promotion of the series of"Jin Lu Yin He "'s combination of 11 products, the first national property portfolio risk insurance industry of insurance products marketing first, put the needs of rural production and living of the family property, personal injury, post-harvest crops, livestock, General Electricity, development of students early childhood, transport of agriculture, and other cadres to practice risk groups divided according to different needs and meet the new requirements of the development of the rural economy effectively.

The past two years, close to People's Insurance according to different consumer groups designed different kinds of insurance products - for specialized work to adapt or go out to populations in need of the physical design of a traffic accident fixed insurance products to meet the child care needs of students in low-cost fixed policy, to adapt to a lower level of rural income needs of low-cost combination Nongjiale policy, to adapt to high-income level of rural households in the demand for new mid-priced portfolio of insurance products in rural areas, according to urban and rural areas designed to ease sharing of accidental injuries, such as a fixed policy promulgated successively later. It is the demand from farmers, the refinement of insurance consumer demand before the agricultural insurance has been the development of space.

\subsubsection{The marketing model based on Agriculture.}

In the new situation of insurance market, the promotion pattern of agricultural insurance will certainly changed dramatically. Now, we need to make the most use of the situation in the rural network, at the same time, downward the rural insurance promotion services division continuously. Now individual marketing teams have been extended to the rural county town gradually. And, we should take advantage of the banks, postal services and other agencies and industry to spread villages, with the help of electricity, credit cooperatives, village committees, etc, to agent insurance services widely. In particular, we should cooperate with the Net of the rural road safety projects, so as to provide risk protection for farm vehicles. According to statistics, at the end of June 2006, Jilin People's Insurance Rural Insurance promotion Services has grown to 309, and 495 salesmen. Agencies and industry have developed to 31 in rural.

\subsubsection{The development of agricultural insurance based on Agro-enterprise}

Current agricultural industrialization economic organizations, especially large-scale agricultural products processing enterprises rapid development of the first farmers, enterprises and farmers on the requirements of the growing insurance business, take part in the proportion of insurance constantly improve, to expedite the development of agricultural insurance to provide a wealth of insurance resources. Under the situation of the Policy-oriented agricultural insurance haven't started yet, if commercial insurance companies can make full use of existing institutions network, portfolio of property, cargo, liability, accident insurance and other insurance products, the rapid classification of batches covering the first agricultural enterprises, can make agricultural insurance developed rapidly .

Head of agricultural industrialization of agricultural enterprises are at or above the county head government offers various kinds of support and validation for naming a large scale, organization Driven many farmers, good reputation, high-tech, management stability, anti-risk ability and so on. Practice shows that the better the quality of such enterprises, 
Loss Prevention convenient, low pay, the overall risk. Agro-enterprises through the first contact farmers, can change over the past one to do a traditional model of insurance, unified propaganda guidance, unity insurance, disaster prevention, claims, Greatly reducing the operating costs of insurance companies, insurance companies or Marketing Support Services Department can undertake this region-related businesses

Insurance salesman from taking the string Tuen retail direct sales model to the rural credit cooperatives, the Agricultural Bank and other institutions and industry promotion channel model; From farmers for the dispersion of bulk single-sales services for the agricultural industry groups EC single-sales Service, insurance companies, promotion service model should be the expansion of diversification. It is precisely this mixed pattern of changes in marketing, in a sense in order to break through a long period of time constraints in the development of rural insurance business huge human inputs and material costs, low rate of business development and some other problems.

\section{References}

Gao, Wei. (2007). The inspiration of Japanese Agricultural insurance development. The financial of Xi'an. 2007. 02. 12-14.

Guo, wenchao \& Liang, Hong. (2006). The research about the model of our country's Agricultural insurance. The theoretical. 2006. 12. 62-65.

Shang, Xiaoyang. (2006). Agricultural insurance: Government Units to sing good ride.China Securities. 2006. 09-20.

Sun, Rong \& Huang, Yingjun. (2007). The Development of Our country's Agricultural insurance:Recalling, Present situation And Prospects. Ecological economy. 2007-01. 26-33. 